3.99 .

The alkaline solution was acidified with $10 \% \mathrm{HCl}$ to give 1,2-diferrocenoylacrylic acid (II) as deep red plates, mp $170-171^{\circ}\left(0.3 \mathrm{~g} ; 4.9 \%\right.$ yield based on unrecovered ferrocene). Anal. Calcd. for $\mathrm{C}_{14} \mathrm{H}_{12} \mathrm{O}_{3} \mathrm{Fe}$ : C, 59.19; H, 4.26. Found: C, 59.13; H, 4.31.

Photooxidation of 2,5-Diferrocenylfuran (VI)__A solution of $\mathrm{VI}^{9)}(0.1 \mathrm{~g})$ in $100 \mathrm{ml}$ of acetone was irradiated with a Ushio-100 W mercury high pressure lamp, while air was bubbled through the mixture at -60 $-80^{\circ}$. After 25 min the solvent was removed in vacuo at room temperature. The residue was chromatographed on alumina to give unreacted VI $(50 \mathrm{mg})$ from benzene elution, and next fraction with ethyl acetate gave trans-1,2-diferrocenoylethylene (I) $(5 \mathrm{mg})$, which was identical with I described above.

\title{
Mechanism of the Color Reaction of Active Methylene Compounds with 1,3,5-Trinitrobenzene Derivatives. VI.1) A Protonated Species of the Meisenheimer Type Compound derived from Picric Acid and Acetone ${ }^{2)}$
}

\author{
Toyoshige Kabeya, Kazuya Kohashi, and Yosuke Ohkura. \\ Faculty of Pharmaceutical Sciences, Kyushu University
}

(Received July 26, 1973)

In the previous paper of this series, $\left.{ }^{4}\right)$ the color reaction of picric acid and acetone under the Janovsky conditions ${ }^{5)}$ was elucidated by isolating disodium salt of the Meisenheimer type anion I (I-2Na) shown in Chart 1 and the bicyclic type compound.<smiles>CC(=O)CC1C=CC(=O)C(=O)C1[N+](=O)[O-]</smiles>

I

Chart 1<smiles>CC(=O)CC1C(=O)C=C(N=O)C=C1[N+](=O)[O-]</smiles>

II

Chart 2

During the course of study on the spectral behavior of aqueous solution of I-2Na, we found that a new species was obtained in crystalline forms when I-2Na was treated with an acid. The new species was stable in an acidic medium, though sodium salt of the Meisenheimer type anion II (Chart 2) derived from 1,3,5-trinitrobenzene (TNB) and acetone was already observed to regenerate the original components on dissolving it in acidic media. $\left.{ }^{6}\right)$ This paper describes the isolation of the new species and its absorption spectral behavior.

1) Part V: K. Kohashi, T. Kabeya, Y. Ohkura, and T. Momose, Chem. Pharm. Bull. (Tokyo), 21, 2187 (1973).

2) This forms "Organic Analysis LXXXIX". Part LXXXVIIT: (1).

3) To whom all inquiries should be addressed. Location: Katakasu, Higashi-ku, Fukuoka.

4) T. Kabeya, K. Kohashi, Y. Ohkura, and T. Momose, Chem. Pharm. Bull. (Tokyo), 21, 2168 (1973).

5) J.V. Janovsky and L. Erb, Ber., 19, 2155 (1886); J.V. Janovsky, ibid., 24, 971 (1891). For reviews see T. Nambara, Bunseki Kagaku, 13, 184 (1964); E. Buncel, A.R. Norris, and K.E. Russell, Quavt. Rev., 22, 123 (1968); K. Kohashi and Y. Ohkura, Kagaku No Ryoiki, 27, 303 (1973).

6) M. Kimura, Yakugaku Zasshi, 73, 1219 (1953); idem, Pharm. Bull. (Japan), 3, 75 (1955). 


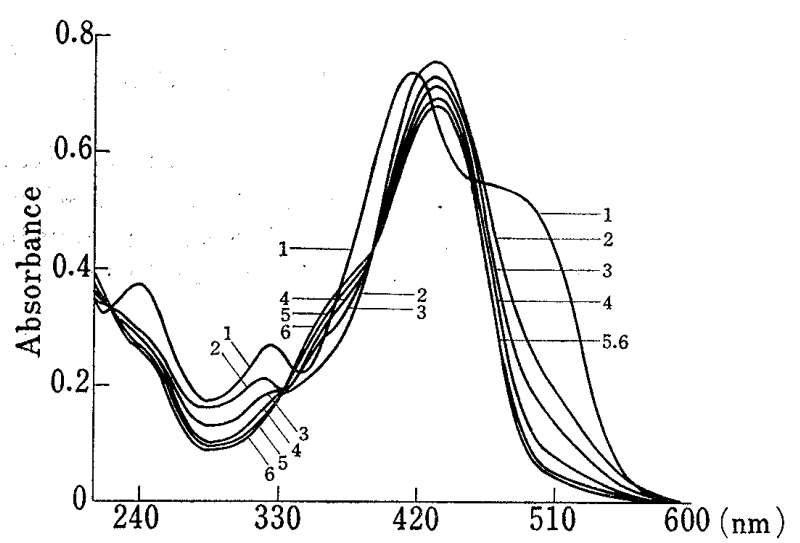

Fig. 1. Absorption Spectral Change of I-2Na in Acidic Solution with Time

1: $2.0 \mathrm{ml}$ of aq. solution of $\mathrm{I}-2 \mathrm{Na}\left(1 \times 10^{-4} \mathrm{M}\right)$ was diluted with $3.0 \mathrm{ml}$ of $\mathrm{H}_{2} \mathrm{O}$.

$2,3,4,5$, and 6: To $2.0 \mathrm{ml}$ of aq. solution of I-2Na in 1 , $1.0 \mathrm{ml}$ each of $\mathrm{H}_{2} \mathrm{O}$ and aq. $2.0 \% \mathrm{H}_{3} \mathrm{PO}_{4}$ were successively added. The solution was kept at $35^{\circ}$ for several periods $(2,1 ; 3,30 ; 4,60 ; 5,90 ; 6,120 \mathrm{~min})$, and diluted with $1.0 \mathrm{ml}$ of $\mathrm{H}_{2} \mathrm{O}$.

The spectra were measured against $\mathrm{H}_{2} \mathrm{O}$.
An aqueous solution of I-2Na showed an absorption spectrum with three maxima at 238, 326, and $420 \mathrm{~nm}$ and a shoulder around $480 \mathrm{~nm}$ (Fig. 1, 1). When a dilute phosphoric acid solution ${ }^{7}$ was added to the solution, the maxima at 238 and 326 $\mathrm{nm}$ and the shoulder around $480 \mathrm{~nm}$ gradually disappeared and the maximum at $420 \mathrm{~nm}$ shifted to $435 \mathrm{~nm}$ (Fig. 1,2-6). The resulting spectrum (Fig. 1, 6) did not change for at least 2 days on standing at room temperature $\left(20^{\circ}\right)$, indicating that the species responsible for the spectrum might be stable in such an acidic solution.

In order to isolate the species, a methanolic solution of $\mathrm{I}-2 \mathrm{Na}$ was treated with acetic acid and yellow needles (III$\mathrm{Na}$ ) were obtained as described in Experimental.

The data of elemental analyses of the

compound were consistent with the formula of $\mathrm{C}_{9} \mathrm{H}_{8} \mathrm{O}_{8} \mathrm{~N}_{3} \mathrm{Na}$.

The infrared (IR) spectrum of III-Na showed the absorptions at 1732 and $1657 \mathrm{~cm}^{-1}$ due to two different carbonyl groups. The former was assigned to the carbonyl group of acetonyl residue and the latter might be ascribable to the carbonyl group of nitrocyclohexenone system. ${ }^{8)} \quad$ Other absorptions at 1565,1370 and $1320,1230,745 \mathrm{~cm}^{-1}$ in the IR spectrum were assigned to those of nitro and nitronate groups, respectively. ${ }^{9}{ }^{\prime}$

From the above data and the nuclear magnetic resonance (NMR) spectral assignments (Fig. 2), the structure of III-Na was determined as monosodium salt of a protonated species of $\mathrm{I}$, as shown in Chart 3.<smiles>COC(=O)C1C(=O)C=CC(=O)C1C(=O)N=O</smiles>

III

Chart 3

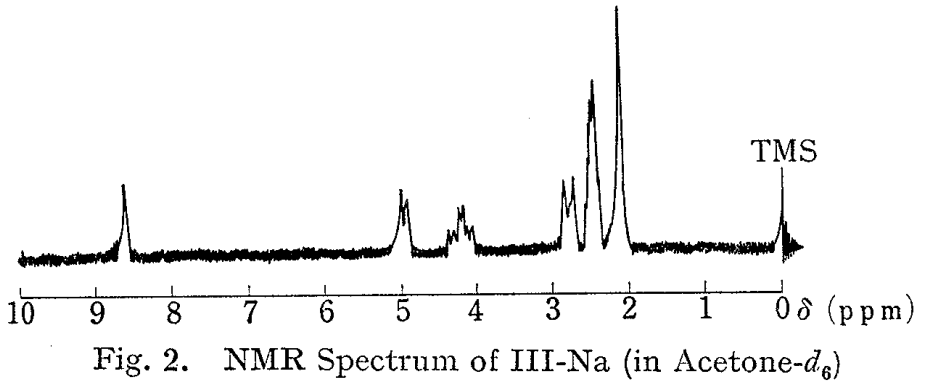

The singlets at $\delta(\mathrm{ppm}) 8.63(1 \mathrm{H})$ and $2.12(3 \mathrm{H})$ were assigned to the proton $\mathrm{He}$ on the dinitropropenide group ${ }^{10)}$ and the methyl protons Ha of acetonyl group, respectively. The

7) Similar spectral changes were also observed on adding each individual acid of sulfuric, nitric, hydrochloric, and acetic acids to an aqueous solution of I-2Na. Their spectra were also stable for more than $12 \mathrm{hr}$ at room temperature $\left(20^{\circ}\right)$.

8) The carbonyl group of potassium 2-keto-3-nitrocyclohexanenitronate was reported to absorb at 1651 $\mathrm{cm}^{-1}$ (H. Feuer, A.M. Hall, S. Golden, and R.L. Reits, J. Org. Chem., 33, 3622 (1968)).

9) K. Nakanishi, "IR Absorption Spectroscopy (Practical Part)," Nankodo, Tokyo, 1960, p. 55.

10) The value of chemical shift of the corresponding proton falls within the range of $\delta .8 .6-8.9$ for $1,3,5$ trinitrocyclohexadienide systems of the Meisenheimer type anions like II (R. Foster and C.A. Fyfe, Tetrahedron, 21, 3363 (1965)) and $\delta 8.6-8.2$ for the dinitropropenide system of the bicyclic type anions (M.J. Strauss and H. Schran, J. Am. Chem. Soc., 91, 3974 (1969); K. Kohashi, Y. Ohkura, and T. Momose, Chem. Pharm. Bull. (Tokyo), 18, $2151(1970)$ ). 
doublet at $\delta 2.7 \dot{8}(2 \mathrm{H}, J=7.2 \mathrm{~Hz})$ was assigned to the methylene protons $\mathrm{Hb}$ of acetonyl group. The doubly splitting triplet at $\delta 4.35(1 \mathrm{H}, J=1.5$ and $7.2 \mathrm{~Hz})$ was assigned to the proton $\mathrm{Hc}$ coupled with the methylene protons $\mathrm{Hb}$ and another proton, which was assigned to $\mathrm{Hd}$ on the $s p^{3}$ ring carbon atom with nitro group. ${ }^{11)}$ The proton Hd appeared as a doublet at $\delta 4.94(1 \mathrm{H}, J=1.5 \mathrm{~Hz})$.

An aqueous solution of III-Na $\left(4 \times 10^{-5} \mathrm{M}\right)$ had a $\mathrm{pH}$ value of 6.0 at $\left.20^{\circ},{ }^{12}\right)$ and showed the absorption band with a maximum at $435 \mathrm{~nm}$ and two shoulders around 250 and $360 \mathrm{~nm}$ (Fig. 3, 1). The spectrum was in fair agreement with that of the acidic solution of I-2Na (Fig. 1,6), suggesting that the spectrum of I-2Na in the acidic solution was due to the formation of anion III. However, the absorption band of the aqueous solution of III-Na gradually changed into other band when the solution was left standing for $1 \mathrm{hr}$ at room temperature $\left(20^{\circ}\right)$. The resulting spectrum remained unchanged and was closely similar to the intermediate bands derived from I-2Na in acidic solutions (Fig. 1, 2-3) and III-Na in neutral solutions described below (Fig. 3, 3-4). In the acidification of the aqueous solution of I-2Na shown in Fig. 1, the initial absorption curve 1 changed rapidly into the curve 2 , and then very slowly into the curve 6 . Whereas, when the $\mathrm{pH}$ values of the aqueous solution of III-Na were adjusted to about 7-9 by adding dilute sodium hydroxide solutions, the maximum at $435 \mathrm{~nm}$ shifted to $413 \mathrm{~nm}$ and three maxima at 485,326 , and $238 \mathrm{~nm}$ appeared (Fig. 3,6 ) through the intermediate bands (Fig. 3, 3-4) which were similar to the curve $2-3$ of Fig. 1 . In the spectral change shown in Fig. 1 and Fig. 3 the isosbestic points were similarly observed at 419,378 , and $343 \mathrm{~nm}$. These observations suggested the presence of an intermediate species in the transformations of the anion I to III vice versa. The intermediate species was assumed to have a structure of a nitronic acid IV or its isomer IV'13) (Chart 4) from a common relationship among a nitro compound, its nitronic acid, and nitronate anion. ${ }^{14)}$ Thus, the changes of the absorption bands of the aqueous solutions of I-2Na and III-Na

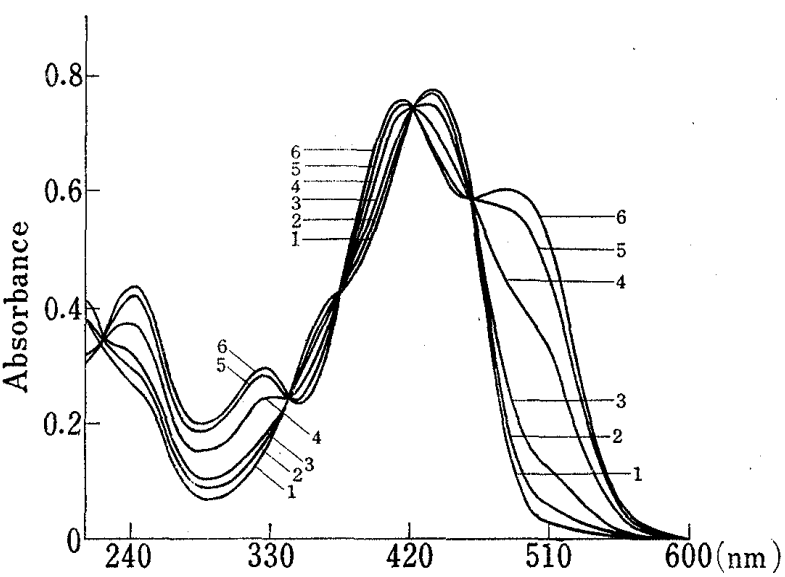

Fig. 3. Absorption Spectra of III-Na in Alkaline Solutions

1: $2.0 \mathrm{ml}$ of aq. solution of III-Na $\left(1 \times 10^{-4} \mathrm{Ma}\right)$ was dilu ted with $3.0 \mathrm{ml}$ of $\mathrm{H}_{2} \mathrm{O}$.

$2,3,4,5$, and $6:$ To $2.0 \mathrm{ml}$ of aq, solution of III-Na in $1,1.0 \mathrm{ml}$ each of $\mathrm{H}_{2} \mathrm{O}$ and variously concentrated $\mathrm{NaOH}$ $(2-6)$ were successively added. The mixture was kept for $30 \mathrm{sec}$ at room temperature (about $25^{\circ}$ ), and diluted with $1.0 \mathrm{ml}$ of $\mathrm{H}_{2} \mathrm{O}$. NaOH concentration $\left(\times 10^{-4} \mathrm{M}\right)$ is 2 , $1 ; 3,2 ; 4,3 ; 5,4 ; 6,5$.

The aq, solution of III-Na was used immediately after preparing it, and the spectra were measured against $\mathrm{H}_{2} \mathrm{O}$ within $60 \mathrm{sec}$ after diluting with $\mathrm{H}_{2} \mathrm{O} . \mathrm{H}_{2} \mathrm{O}$ used was free from $\mathrm{CO}_{2}$.

described above would be successfully explained by the equilibria among the anions I, IV or IV', and III (Chart 5).

On the other hand, when a higher concentrated sodium hydroxide solution was added to the aqueous solution of III-Na, the mixture showed almost the same spectral change as that of I-2Na, as described in the previous paper. ${ }^{4)}$

11) Similar structural protons were reported to absorb in a range of $\delta 5.0-5.4$ for 1,3,5-trinitrocyclohexadienide systems ${ }^{10)}$ and at $\delta 4.82$ for 2 -nitro-3,5,5-trimethylcyclopentanone (H. Feuer and P.M. Pivawer, J. Org. Chem., 31, $3152(1966)$ ).

12) $\mathrm{pH}$ value was measured by a Hitachi-Horiba $\mathrm{pH}$ Meter M-7. Sample was dissolved in distilled water free from carbon dioxide.

13) The formation of the anion IV' in the reaction of picric acid and acctone in alkaline medium has already been proposed (M. Kimura, Pharm. Bull. (Japan), 3, 81 (1955)).

14) A.T. Nielson, "Nitronic Acids and Esters" in "The Chemistry of the Nitro and Nitroso Groups," Part 1, ed. by S. Patai, Interscience (John Wiley \& Sons), New York, 1969, p. 349. 
<smiles>CC(=O)CC1C(=O)C(=O)C([N+](=O)[O-])C=C1C(=O)O</smiles>

IV<smiles>CC(=O)CC1C(=O)C=C([N+](=O)[O-])C(O)C1=[N+]([O-])[O-]</smiles>

$\mathrm{IV}^{\prime}$
I $\underset{\mathrm{OH}^{-}}{\stackrel{\mathrm{H}^{+}}{\rightleftarrows}} \mathbb{N}$ or $\mathbb{I}^{\prime} \underset{\mathrm{OH}^{-}}{\stackrel{\mathrm{H}^{+}}{\rightleftarrows}} \mathrm{III}$

Chart 5

Chart 4

\title{
Experimental $\left.{ }^{15}\right)$
}

Preparation of III-Na-I-2Na $(0.5 \mathrm{~g})$ was dissolved in a mixture of $\mathrm{MeOH}(10 \mathrm{ml})$ and AcOH $(3 \mathrm{ml})$. After standing for $10-12 \mathrm{hr}$ at room temperature (about $25^{\circ}$ ), the solvent was removed in vacuo at $50^{\circ}$.

The residue was dissolved in AcOEt $(10 \mathrm{ml})$ and filtered, yellow needles were obtained. Yield, $0.28 \mathrm{~g}$. mp $175^{\circ}$ (decomp.) (from EtOH). Anal. Calcd. for $\mathrm{C}_{9} \mathrm{H}_{8} \mathrm{O}_{8} \mathrm{~N}_{3} \mathrm{Na}: \mathrm{C}, 34.95 ; \mathrm{H}, 2.59 ; \mathrm{N}, 13.59 ; \mathrm{Na}, 7.44$. Found: $\mathrm{C}, 34.95 ; \mathrm{H}, 2.66 ; \mathrm{N}, 13.72 ; \mathrm{Na}, 7.29 . \lambda_{\max }^{\mathrm{H}_{2} \mathrm{O}} \mathrm{nm}(\varepsilon): 435(19300)$.

Acknowledgement The authors express their gratitude to Mr. H. Matsui and Miss Y. Soeda for the IR spectral measurement, to Mr. K. Ishimura and Miss Y. Kanzaki for the elemental analysis and to Mr. Y. Tanaka for the NMR spectral measurement.

15) UV absorption spectra were measured by a Hitachi 124 Spectrophotometer equipped with a Hitachi 056 Recorder in a cell of $10 \mathrm{~mm}$ optical length. IR spectra were measured by a Nihonbunko DS-701G Infrared Spectrophotometer in $\mathrm{KBr}$ pellet. NMR spectra were measured by a JEOL C-60H NMR Spectrometer using tetramethylsilane (TMS) as an internal standard.

\section{Metabolism of Drugs. LXXXI. ${ }^{1)}$ Further Studies on Metabolism of Prolintane in Rabbits}

\author{
Shin-Ichi Yoshihara and Hidetoshi Yoshimura \\ Faculty of Pharmaceutical Sciences, Kyushu University ${ }^{2)}$
}

(Received August 6, 1973)

In the previous paper ${ }^{3)}$ we reported the in vivo metabolism of prolintane, 1-phenyl-2pyrrolidinopentane hydrochloride in rabbits after oral administration. Rabbits receiving the drug excreted seven metabolites together with a trace amount of unchanged compound in the $24 \mathrm{hr}$ urine. These were shown to be oxoprolintane, $p$-hydroxyprolintane, $(\omega-1)$ hydroxyprolintane, $p$-hydroxyoxoprolintane, diastereoisomeric two ( $\omega$-1)-hydroxyoxoprolintanes and amino acid derivative (PPGABA). ${ }^{4}$ On the basis of quantitative analysis, it was

1) Part LXXX: K. Tatsumi, T. Yamaguchi and H. Yoshimura, Chem. Pharm. Bull. (Tokyo), 21, 622 (1973).

2) Location: Katakasu, Higashi-ku, Fukuoka.

3) S. Yoshihara and H. Yoshimura, Chem. Pharm. Bull. (Tokyo), 20, 1906 (1972).

4) Abbreviations used are as follows; oxoprolintane: 1-phenyl-2-(2-oxopyrrolidino)pentane; $p$-hydroxyprolintane: 1-(4-hydroxyphenyl)-2-pyrrolidinopentane; $(\omega-1)$-hydroxyprolintane: 1-phenyl-2-pyrrolidino4-hydroxypentane; $p$-hydroxyoxoprolintane: 1-(4-hydroxyphenyl)-2-(2-oxopyrrolidino) pentane; $(\omega-1)$ hydroxyoxoprolintane: 1-phenyl-2-(2-oxopyrrolidino)-4-hydroxypentane; PPGABA; N-(1-phenyl-2pentyl) $-\gamma$-aminobutyric acid. 